\title{
Use of MALDI-TOF MS and culturomics to identify mosquitoes and their midgut microbiota
}

Fatalmoudou Tandina ${ }^{1,2}$, Lionel Almeras ${ }^{1,3}$, Abdoulaye K. Koné2, Ogobara K. Doumbo², Didier Raoult ${ }^{1}$ and Philippe Parola ${ }^{1 *}$

\begin{abstract}
Background: Mosquitoes transmit a wide range of human parasitic and viral diseases. In recent years, new techniques such as MALDI-TOF MS have been developed to identify mosquitoes at the species level, which is key for entomological surveys. Additionally, there is increasing interest in the mosquito microbiota and its role in vector capacity.

Methods: The culturomics approach previously used in our laboratory to study human gut microbiota was applied to evaluate the midgut bacterial diversity of Anopheles gambiae (wild and laboratory strains), Aedes albopictus (wild and laboratory strains) and Culex quinquefasciatus (wild strains) in order to determine the influence of the environmental status on the midgut microbiota of the mosquitoes.

Results: Mosquitoes collected in the field were accurately identified by MALDI-TOF MS analysis of their legs. Adult mosquito midgut microbiota was composed of four phyla, including Proteobacteria, Bacteroidetes, Actinobacteria and Firmicutes. The majority of the bacteria detected in the microbiota of mosquitoes were gram-negative and belong to the phylum Proteobacteria. MALDI-TOF MS identified for the first time a new bacterial species from An. gambiae midgut microbiota.
\end{abstract}

Conclusion: In this study, the culturomics approach was found to be a reliable technique for exploring the diversity of the mosquito microbiota. MALDI-TOF MS was confirmed as a promising technique to identify mosquitoes collected in the field. Culturomics allowed the isolation of a new bacterial species not previously associated with mosquito vectors. The environment plays a role in the bacterial diversity of the microbiota, which could enable the development of new control strategies for mosquito-borne disease.

Keywords: Anopheles gambiae Giles, Aedes albopictus, Culex quinquefasciatus, Culturomics, MALDI-TOF MS, Microbiota

Abbreviations: $16 \mathrm{~S}$ rRNA, $16 \mathrm{~S}$ ribosomal ribonucleic acid; B, Bacillus; C, Culex; HPLC, High-performance liquid chromatography; LSV, Log score value; MALDI-TOF MS, Matrix-Assisted Laser Desorption Ionization Time-Of-Flight Mass Spectrometry; MRTC, Malaria Research and Training Center; URMITE, Unité de Recherche sur les Maladies Infectieuses et Tropicales Emergentes

\footnotetext{
*Correspondence: philippe.parola@univ-amu.fr

'Unité de Recherche en Maladies Infectieuses et Tropicales Emergentes

(URMITE), UM63, CNRS 7278, IRD 198 (Dakar, Sénégal), Inserm 1095, Faculté

de Médecine, Aix Marseille Université, 27 bd Jean Moulin, 13385 Marseille

cedex 5, France

Full list of author information is available at the end of the article
} 


\section{Background}

There are over 3500 different species of mosquitoes with a worldwide distribution [1]. The most described species that are able to transmit pathogens to humans and animals belong to the genera Aedes, Culex and Anopheles [1]. Mosquito vectors are not limited to tropical areas, where malaria, dengue and chikungunya are well-known threats for the local population and travellers [2, 3]. The tiger mosquito, Aedes albopictus, is an invasive species that has spread across the world in the last two decades [4]. The global expansion of Ae. albopictus may modify the worldwide epidemiology of arbovirus and increase the risk to humans of mosquito-borne diseases [5]. Culex spp. mosquitoes include vectors of human diseases such as arboviral diseases and lymphatic filariasis [1]. Anopheles gambiae (s.l.) mosquitoes are the major malarial vectors in sub-Saharan Africa [6]. Malaria parasites are transmitted from human to mosquito when a female Anopheles ingests a gametocyte-infected blood meal [6]. In the mosquito midgut, malaria parasites undergo a series of complex developmental stages and transmission depends on the success of the different transition steps [7].

Studies on the role of the microbiota within the gut of insects have increased in recent years $[8,9]$. This has led to an intensification of studies focused on the microbiota of diverse mosquito species, including a potential influence on their vector competence $[9,10]$. Some studies have shown the impact of the mosquito midgut microbiota in the defense against malaria parasites, with Enterobacteriaceae affecting the development of $P$. falciparum in the $A n$. gambiae mosquito midgut [7]. Moreover, by using antibiotic treatments to clear the midgut microbiota, other studies have suggested a protective role of $A n$. gambiae midgut bacteria against Plasmodium infections $[11,12]$. It has also been suggested that antibiotics in ingested blood enhance the susceptibility of An. gambiae mosquitoes to malarial infection by disturbing their gut microbiota. In addition, antibiotic exposure increases mosquito survival and fecundity, which are factors increasing vectorial capacity [13].

In recent years, a new approach using special cultures, named culturomics, has been developed in our laboratory for the identification of not only the human gut microbiota, including common bacteria, but also minority bacterial populations [14]. Here, we used a culturomics approach to study the midgut bacterial diversity of three mosquito species, including wild and laboratory strains. The bacterial patterns of mosquito species reared in the laboratory were compared to mosquitoes collected in the field within their respective water sites to assess the effect of the environment on bacterial populations.

\section{Methods}

\section{Laboratory-reared mosquitoes}

An. gambiae Giles laboratory colonies and Ae. albopictus collected in the south of France in June 2013 were maintained by breeding at our laboratory in Marseille, France. Briefly, Ae. albopictus and An. gambiae from the laboratory were reared using standard methods at a temperature of $26 \pm 1{ }^{\circ} \mathrm{C}$, a relative humidity of 70-90\% and a photoperiod of $12 \mathrm{~h}$ (light/dark) in standalone incubators (Panasonic cooled incubator) [15]. After emerging from the pupae, the adults $A n$. gambiae and Ae. albopictus were fed with a $10 \%(\mathrm{w} / \mathrm{v})$ sucrose solution. For egg production, blood meals were given through a parafilm membrane (Hemotek membrane feeding systems, Discovery Workshops, Accrington, England, UK) using fresh heparinized sheep blood over $1 \mathrm{~h}$ [5]. The blood-feeding was performed every three days, according to the gonotrophic cycle. Engorged female An. gambiae and Ae. albopictus were transferred into another cage and were maintained in standard conditions with $10 \%(\mathrm{w} / \mathrm{v})$ sucrose solution on cotton. Larvae were reared to the nymph stage in trays containing distilled water. Pupae were collected daily and transferred to mosquito cages (Bug Dorm 1, BioQuip Products, Gladwick Street, USA). Larvae were fed with fish food (TetraMin) until the pupal stage [16]. To explore the midgut microbiota of the laboratory mosquito colonies, the midguts of six specimens of $A n$. gambiae and five specimens of Ae. albopictus were dissected.

Newly emerged adult An. gambiae specimens from our laboratory colonies were used in the present work. These anopheline mosquitoes were collected immediately after emergence and maintained under standard conditions and fed only with $10 \%(\mathrm{w} / \mathrm{v})$ sucrose solution for three days. Female mosquitoes were engorged on human blood (defibrinated human blood) over one hour. Anopheles gambiae females (three specimens) engorged on human blood were sacrificed $24 \mathrm{~h}$ after the blood meals (at day one) and midgut dissection was immediately performed under sterile conditions.

Additionally, one male and one female adult specimen from the F1 generation, resulting from $A n$. gambiae female specimens who were fed on blood, were sacrificed $24 \mathrm{~h}$ after their emergence. There were a total of $12 A n$. gambiae specimens, including male $(n=3)$ and female $(n=3)$ specimens fed only on sucrose solutions, and females fed on human blood $(n=3)$. In addition, one male and one female adult specimen of the F1 generation of these last two groups were also tested. In this second experiment there was a sequential collection (i.e. D1, D3, D8 and F1) of mosquito midguts. Midguts were collected and analysed by culturomics. 


\section{Mosquitoes in the wild Collection of wild mosquitoes}

Aedes albopictus was captured in Marseille by human landing catches in the garden of the Faculty of Medicine in August 2014. The collected Ae. albopictus mosquitoes were individually conserved in caps prior to transport to the laboratory. In Mali, 53 An. gambiae (s.l.) and 204 Culex spp. mosquitoes were captured using the CDC light trap from the Sikasso region (south Mali) from April to May, 2014. Specimens were sterilized in $70 \%$ ethanol (2-10 $\mathrm{min}$ ) and then rinsed in distilled water. Each adult mosquito was transferred individually to a $1.5 \mathrm{ml}$ Eppendorf tube and the specimens were then kept at $-80{ }^{\circ} \mathrm{C}$ and sent frozen to the URMITE laboratory (Marseille, France).

\section{Identification of wild mosquitoes}

The collected specimens were initially identified using morphological criteria [17]. Additionally, each specimen was submitted to MALDI-TOF MS for identification as previously described $[18,19]$. Legs from each mosquito were homogenized manually in $20 \mu \mathrm{l}$ of $70 \%$ (v/v) formic acid and $20 \mu \mathrm{l}$ of $50 \%(\mathrm{v} / \mathrm{v})$ acetonitrile in $1.5 \mathrm{ml}$ microtubes using pellet pestles (Fischer Scientific, Strasbourg, France). The homogenates were centrifuged at $10,000 \mathrm{rpm}$ for $20 \mathrm{~s}$, and $1 \mu \mathrm{l}$ of the supernatant of each sample was deposited on a steel target plate (Bruker DaltonicsTM, Wissembourg, France) into four spots for each sample [18]. Then, $1 \mu \mathrm{l}$ of CHCA matrix composed of saturated a-cyano-4-hydroxycynnamic acid (SigmaH, Lyon. France), $50 \%(\mathrm{v} / \mathrm{v})$ acetonitrile, $2.5 \%$ (v/v) trifluoroacetic acid and HPLC-grade water was directly overlaid on each sample on the target plate, dried for several minutes at room temperature and introduced into the MALDI-TOF MS instrument for analysis [19].

Protein mass profiles were obtained using Microflex LT MALDI-TOF Mass Spectrometry (Bruker Daltonics, Germany) with Flex Control software (Bruker Daltonics, Germany) as previously described [18, 20]. Measurements were performed in the linear positive-ion mode within a mass range of 2-20 kDa. Each spectrum corresponds to ions obtained from 240 laser shots performed in six regions of the same spot. The spectrum profiles obtained were visualized with flexAnalysis 3.3 software and exported to the MALDI Biotyper v. 3.0 (Bruker Daltonics, Germany) [19].

Molecular tools were also used to confirm the identification of some mosquitoes. DNA extractions from individual mosquito heads and thorax samples were performed with the EZ1 DNA Tissue Kit (Qiagen, Hilden, Germany) according to manufacturer recommendations. A set of primers specifically amplifying a fragment of the mosquito cytochrome $c$ oxidase subunit I gene (mCOI) was used (LCO1490 (forward):5'-GGT CAA CAA ATC ATA AGATAT
TGG-3'; HC02198 (reverse): 5'-TAA ACT TCA GGG TGA CCA AAA AAT CA-3') [21]. The PCR reaction contained $13 \mu \mathrm{l}$ of sterile distilled water, $2.5 \mu \mathrm{l}$ of $10 \mathrm{X}$ Phusion HF Buffer (15 mM), $2.5 \mu \mathrm{l}$ of dNTPs $(2 \mathrm{mM}), 0.5 \mu \mathrm{l}$ of each primer $(10 \mu \mathrm{M}), 0.25 \mu \mathrm{l}$ of Hot star Taq (5units/ $\mu \mathrm{l}), 1 \mu \mathrm{l}$ of $\mathrm{MgCl}_{2}$ $(25 \mathrm{mM})$ and $5 \mu \mathrm{l}$ of extracted DNA. Reactions were amplified through 35 cycles at the following parameters: $10 \mathrm{~min}$ at $95{ }^{\circ} \mathrm{C}, 1 \mathrm{~min}$ at $95{ }^{\circ} \mathrm{C}, 1 \mathrm{~min}$ at $40{ }^{\circ} \mathrm{C}, 1.5 \mathrm{~min}$ at $72{ }^{\circ} \mathrm{C}$, followed by a final extension step at $72{ }^{\circ} \mathrm{C}$ for $7 \mathrm{~min}$.

A set of primers specifically amplifying a fragment of 310 bp of the An. gambiae mosquito complex > Acomplex_28S_MBF AGC KCG TCT TGG TCT GGG G and > Acomplex_28S_MBR GCC GAC AAG CTC AYT AGT GT were designed in the URMITE laboratory based on the publication of Fanello et al., and PCR reactions were processed as described [22]. Positive PCR products were then purified and sequenced using the same respective primers with the BigDye version 1-1 Cycle Sequencing Ready Reaction Mix (Applied Biosystems, Foster City, CA) and an ABI 3100 automated sequencer (Applied Biosystems). The sequences were assembled and analyzed using the ChromasPro software (version 1.34) (Technelysium Pty. Ltd., Tewantin, Australia) and BLAST website (http://blast.ncbi.nlm.nih.gov).

\section{Water from breeding sites}

For mosquito colonies reared in the laboratory (i.e. $A n$. gambiae and Ae. albopictus), $200 \mu \mathrm{l}$ of the laboratory breeding water was collected with a Pasteur pipette and put into the $1.5 \mathrm{ml}$ Eppendorf sterile tubes for culturomics analyses. Breeding water was then used for the culturomics experiments to control and compare the bacterial diversity between the environmental breeding site and the adult mosquito midgut.

The breeding water of the wild mosquitoes from Marseille was recovered with a ladle near the place where the mosquitoes had been collected on humans. The water was then transferred to a $15 \mathrm{ml}$ sterile tube and transported to the laboratory. In the Sikasso region, in Mali, three breeding water sites were selected and collected with ladle sampling, prior to being transferred to a $15 \mathrm{ml}$ sterile tube and transported to the laboratory. Then, the samples were stored at $-80{ }^{\circ} \mathrm{C}$ until they were transported frozen to URMITE. Each breeding site was geo-positioned as follows: breeding site $1\left(-5^{\circ} 66^{\prime} 13.1^{\prime \prime} \mathrm{N}, 1^{\circ} 30^{\prime} 95.2^{\prime \prime} \mathrm{E}\right)$; breeding site $2\left(-5^{\circ} 60^{\prime} 80.6^{\prime \prime} \mathrm{N}, 11^{\circ} 30^{\prime} 30.6^{\prime \prime} \mathrm{E}\right)$ and breeding site 3 $\left(-5^{\circ} 60^{\prime} 73.8^{\prime \prime} \mathrm{N}, 11^{\circ} 30^{\prime} 58.0^{\prime \prime} \mathrm{E}\right)$.

\section{Mosquito gut dissection}

Adult mosquitoes were anesthetized with cold at $-20{ }^{\circ} \mathrm{C}$ for $10 \mathrm{~min}$. All midgut mosquitoes from laboratory 
colonies (An. gambiae and Ae. albopictus) and wild mosquitoes were dissected under sterile conditions. Mosquitoes were surface-sterilized in $70 \%(\mathrm{v} / \mathrm{v})$ ethanol for $2-$ $10 \mathrm{~min}$, then rinsed three times in a sterile saline buffer $0.9 \%(\mathrm{w} / \mathrm{v}) \mathrm{NaCl}$ (Laboratoires Gilbert, France). The midgut was carefully removed under a stereo microscope (10× magnification) using clean forceps.

Midguts from the An. gambiae laboratory colony, Ae. albopictus laboratory colony and Ae. albopictus wild colony were placed individually and midguts from the $A n$. gambiae wild colony and C. quinquefasciatus wild colony were pooled in sterile Eppendorf tubes containing $200 \mu \mathrm{l}$ of $0.9 \%$ (w/v) NaCl (Laboratoires Gilbert, France) and homogenized using a single-use pestle and centrifuge and vortex [23, 24]. There were a total of six $A n$. gambiae from the laboratory in Marseille for the first experiment and $12 \mathrm{An}$. gambiae from the laboratory in Marseille for the second experiment; five Ae. albopictus from the laboratory in Marseille, four mosquitoes fieldcollected in Marseille and twelve mosquitoes fieldcollected in Mali.

\section{Culturomics procedure}

The standard and optimal conditions for the culturomics approach were used, based on previous work performed in our laboratory, notably for research on the human gut microbiota [14]. This technique started with preincubation: a special liquid media comprising $15 \mathrm{~g} / \mathrm{l}$ brain heart infusion (Becton, Dickinson and Company, Sparks, MD 21152 USA; 38800 Le Pont-de-Claix, France), 5 g/l Bacto yeast extract (Becton, Dickinson and Company, Sparks, MD 21152 USA; 38800 Le Pont-de-Claix, France), $5 \mathrm{~g} / \mathrm{l}$ proteose peptone (Oxoid Ltd, Basingstoke, Hampshire, England), $1000 \mathrm{ml}$ of sterile water (Fresenius Kabi France, 5 Place de Marivel, 92310 Sèvres, France) and $5 \%$ $(\mathrm{v} / \mathrm{v})$ sheep blood in aerobic and anaerobic conditions at $28{ }^{\circ} \mathrm{C}$ for 1 month. We inoculated them on $5 \%(\mathrm{v} / \mathrm{v})$ sheep blood agar (bioMérieux, Marcy l'Etoile, France) after performing ten serial dilutions from $1 / 10$ to $1 / 10^{-10}$, allowing the growth of fastidious bacteria in order to isolate a maximum of bacterial species. This operation was carried out every 5 days from day 1 to day 25 (i.e. D1, D5, D10, D15, D20 and D25). Bacterial colonies were then isolated on $5 \%(\mathrm{v} / \mathrm{v})$ sheep blood agar after $24 \mathrm{~h}$, and submitted to mass spectrometry (MALDI-TOF MS) for identification. Bacteria not identified by MALDI-TOF MS were then submitted to molecular biology for taxonomic determination by $16 \mathrm{~S}$ sequencing.

\section{Bacterial identification}

\section{Mass spectrometry (MALDI-TOF)}

Each bacterial colony obtained from culture was deposed in duplicate directly onto a MALDI-TOF plate target (Bruker DaltonicsTM, Wissembourg, France) and covered with $1.5 \mu \mathrm{l}$ of the matrix solution composed of a saturated solution of $\alpha$-cyano-4-hydroxycinnamic acid (SigmaH, Lyon, France) diluted in $500 \mu \mathrm{l}$ of acetonitrile $50 \%(\mathrm{v} / \mathrm{v}), 250 \mu \mathrm{l}$ of trifluoroacetic acid $10 \%(\mathrm{v} / \mathrm{v})$ and $250 \mu \mathrm{l}$ of HPLC water and dried for several minutes at room temperature. The target plate was then submitted to MALDI-TOF mass spectrometry for bacterial identification as previously described [25]. To control loading on mass spectra steel, matrix quality and MALDI-TOF apparatus performance, the matrix solution was loaded in duplicate onto each MALDI-TOF plate with and without a Bacterial Test Standard (Bruker Protein Calibration Standard I). A Microflex LT MALDI-TOF mass spectrometer (Bruker Daltonics, Germany) was used for bacterial identification according to the manufacturer's recommendations. Spectra were recorded in a linear mode, within a mass range of 2,000 to 20,000 Daltons (Da). For each spectrum, data for multiple laser shots were collected, summed and analysed. A maximum of 100 peaks was used for each spectrum, and these peaks were compared with the computer database at the Bruker base and the lab-specific base at La Timone hospital. An isolate was considered to be correctly and significantly identified at the species level when the queried spectrum had a log score value (LSV) $\geq 1.9$ [26]. Every unidentified colony was tested successively three times. When the strain remained unidentified, the 16S rRNA gene was sequenced. Spectra from new bacteria species not yet included in the database and identified by $16 \mathrm{~S}$ rRNA sequencing were added to the database.

\section{$16 \mathrm{~S}$ rRNA gene sequencing}

Identification with $16 \mathrm{~S}$ rRNA gene sequencing was performed for the bacteria not identified by MALDI-TOF MS. For this, the bacterial strain was suspended in $200 \mu \mathrm{l}$ of sterile water and was heated at $100{ }^{\circ} \mathrm{C}$ for $10 \mathrm{~min}$. The $16 \mathrm{~S}$ rRNA gene was amplified by PCR using the universal primer pair fd1 and $\mathrm{rp} 2$ and an annealing temperature of $52{ }^{\circ} \mathrm{C}$. The PCR products were purified using a NucleoFast 96 PCR kit (Nanogen, San Diego, USA). The sequence reactions were performed with the BigDye Terminator v1.1 Cycle Sequencing Kit (PerkinElmer), with primers fd1, rp2, 536 F, 536R, 800 F, 800R, $1050 \mathrm{~F}$ and 1050R (Table 1). The products of the sequencing reaction were purified, and the sequences were analysed using an ABI PRISM 3130xl Genetic Analyzer (Applied Biosystems). The obtained sequences were compared with the GenBank database using BLAST software. A threshold similarity value of $>98.7 \%$ was chosen for identification at the species level [27]. Below this value, a new species was suspected, and the isolated strain was characterized in detail using phenotypic analyses and electron microscopy and genome sequencing. 
Table 1 List of primers used for $16 \mathrm{~S}$ rRNA amplification and sequencing

\begin{tabular}{lll}
\hline Primers names & Primer sequences $\left(5^{\prime}-3^{\prime}\right)$ & Temperature $\left({ }^{\circ} \mathrm{C}\right)$ \\
\hline $\mathrm{fd} 1$ & AGA GTT TGA TCC TGG CTC AG & 52 \\
rp2 & ACG GCT ACC TTG TTA CGA CT & 52 \\
$536 \mathrm{~F}$ & CAG CAG CCG CGG TAA TAC & 50 \\
$536 \mathrm{R}$ & GTA TTA CCG CGG CTG CTG & 50 \\
$800 \mathrm{~F}$ & ATT AGA TAC CCT GGT AG & 50 \\
$800 \mathrm{R}$ & CTA CCA GGG TAT CTA AT & 50 \\
$1050 \mathrm{~F}$ & TGT CGT CAG CTC GTG & 50 \\
$1050 \mathrm{R}$ & CAC GAG CTG ACG ACA & 50 \\
\hline
\end{tabular}

\section{Results}

Identification of the mosquitoes collected in the field

Four mosquitoes were collected using the human landing catches method in the Timone hospital garden (Marseille, France). They were morphologically identified as Ae. albopictus specimens. The submission of their legs for MALDI-TOF MS analysis confirmed that the four specimens were Ae. albopictus (LSVs > 1.9).

In Sikasso, Mali, 257 were mosquitoes captured with the CDC light trap, 53 and 204 were identified by morphologic keys as An. gambiae (s.l.) and 204 Culex spp. mosquitoes, respectively. Legs of $6 A n$. gambiae (s.l.) and 6 Culex spp. specimens were submitted to MALDI-TOF MS for identification. MALDI-TOF MS results confirmed the morphological identification of An. gambiae (s.l.) (LSVs > 1.9) and revealed that Culex spp. specimens were all C. quinquefasciatus (LSVs > 1.9). Among these fieldcollected mosquitoes in Mali, six An. gambiae and six C. quinquefasciatus were selected for analysis of their microbiota.
Mosquitoes reared in the laboratory and their respective breeding water

In the first experiment, the midgut microbiota of six $A n$. gambiae from the laboratory colony were analysed by culturomics. A wide variety of bacteria were found at the end of the sequential 1-month culture. A total of ten distinct bacterial species were identified (Table 2). Bacterial diversity included three phyla: Proteobacteria (50\%), Firmicutes (30 \%) and Bacteroidetes (20\%). Two bacterial species, Cedecea lapagei and Serratia marcescens, were isolated in five midguts (83\%) among the six tested. Enterococcus faecium, Elizabethkingia meningoseptica and Serratia ureilytica were isolated in four midguts $(67 \%)$. Elizabethkingia miricola, Enterobacter cloacae, Enterococcus avium, Enterococcus raffinosus and Enterobacter kobei were less frequently detected in the six midguts of the An. gambiae tested (Table 2).

In a second experiment, 12 An. gambiae specimens of the laboratory colony were used. A total of 16 distinct bacterial species were identified belonging to 12 genera: Enterococcus, Enterobacter, Serratia, Acinetobacter, Elizabethkingia, Microbacterium, Staphylococcus, Streptococcus, Cedecea, Pseudomonas, Rhodococcus and Klebsiella in An. gambiae mosquito midguts (Table 3). This diversity is composed of the bacteria of four phyla: Proteobacteria (60\%), Firmicutes (20\%), Bacteroidetes (6.67 \%) and Actinobacteria (13.33\%) (Table 3). A total of six bacterial species were common to An. gambiae midgut and breeding water, and seven bacterial species were found only in the breeding water (Table 3 ).

A wide variety of bacteria in the midgut of Ae. albopictus from the laboratory was observed. A total of 11 distinct bacterial species were identified in mosquito midguts (Fig. 1). Acinetobacter baylyi were isolated in three midguts (60\%). Acinetobacter guillouiae, Achromobacter xylosoxidans, Cedecea lapagei, Cedecea neteri, Serratia

Table 2 List of bacteria identified in the midguts of Anopheles gambiae bred under laboratory conditions

\begin{tabular}{|c|c|c|c|c|c|c|}
\hline Bacteria & Midgut 1 & Midgut 2 & Midgut 3 & Midgut 4 & Midgut 5 & Midgut 6 \\
\hline Cedecea lapagei & & $x$ & $x$ & $x$ & $x$ & $x$ \\
\hline Enterococcus faecium* ${ }^{*}$ & $\times$ & $\times$ & & $x$ & $x$ & \\
\hline Elizabethkingia miricola* & $x$ & & $x$ & & $x$ & \\
\hline Elizabethkingia meningoseptica & $\times$ & & $\times$ & & $x$ & $\times$ \\
\hline Enterobacter cloacae & & $\times$ & & & & $\times$ \\
\hline Serratia marcescens & & $\times$ & $\times$ & $\times$ & $\times$ & $\times$ \\
\hline Enterococcus avium* & & & $x$ & & & \\
\hline Enterococcus raffinosus* & & & $x$ & $x$ & $x$ & \\
\hline Serratia ureilytica* & & $\times$ & $x$ & $x$ & $\times$ & \\
\hline Enterobacter kobei* & & $\times$ & & & & $x$ \\
\hline
\end{tabular}

Bacterial species reported for the first time in Anopheles gambiae are indicated by an asterisk. Presence of bacteria is indicated by $\times$. Bold corresponds to bacterial species common in the midgut and breeding water 
Table 3 List of bacteria identified in the midguts of laboratory-bred Anopheles gambiae non-engorged or engorged and in breeding water

\begin{tabular}{|c|c|c|c|c|}
\hline Bacteria & Female fed on blood & Female sj & Male & Breeding water \\
\hline Aeromonas hydrophila & & & & $x$ \\
\hline Aeromonas jandaei & & & & $\times$ \\
\hline Klebsiella oxytoca & & & $\times$ & $\times$ \\
\hline Enterococcus faecium & & & & $\times$ \\
\hline Enterobacter asburiae* & & $\times$ & $x$ & $\times$ \\
\hline Enterobacter kobei* & $\times$ & $\times$ & $\times$ & $\times$ \\
\hline Serratia marcescens & $x$ & $\times$ & $x$ & $\times$ \\
\hline Serratia fonticola & & & & $\times$ \\
\hline Serratia ureilytica* & $x$ & & & $\times$ \\
\hline Serratia plymuthica & & & & $\times$ \\
\hline Bacillus cereus & & & & $x$ \\
\hline Sphingobacterium multivorum & & & & $\times$ \\
\hline Oceanobacillus massiliensis & & & & $x$ \\
\hline Acinetobacter baylyi* & & & $x$ & \\
\hline Elizabethkingia meningoseptica & $x$ & $x$ & $x$ & \\
\hline Microbacterium maritypicum* & & $\times$ & & \\
\hline Staphylococcus epidermidis* & & $\times$ & & \\
\hline Streptococcus sanguinis* & & $x$ & & \\
\hline Streptococcus mitis* & $x$ & & & \\
\hline Cedecea lapagei & $x$ & & $x$ & \\
\hline Pseudomonas gessardii* & $x$ & & & \\
\hline Rhodococcus erythropolis* & $x$ & & & \\
\hline Enterobacter cloacae & $x$ & $\times$ & $x$ & \\
\hline
\end{tabular}

Bacterial species reported for the first time in Anopheles gambiae are indicated by an asterisk. Presence of bacteria is indicated by $\times$. Bold corresponds to bacterial species common in the midgut and breeding water

Abbreviations: sj, sample from a female fed only on sweet juice, corresponding to the negative control

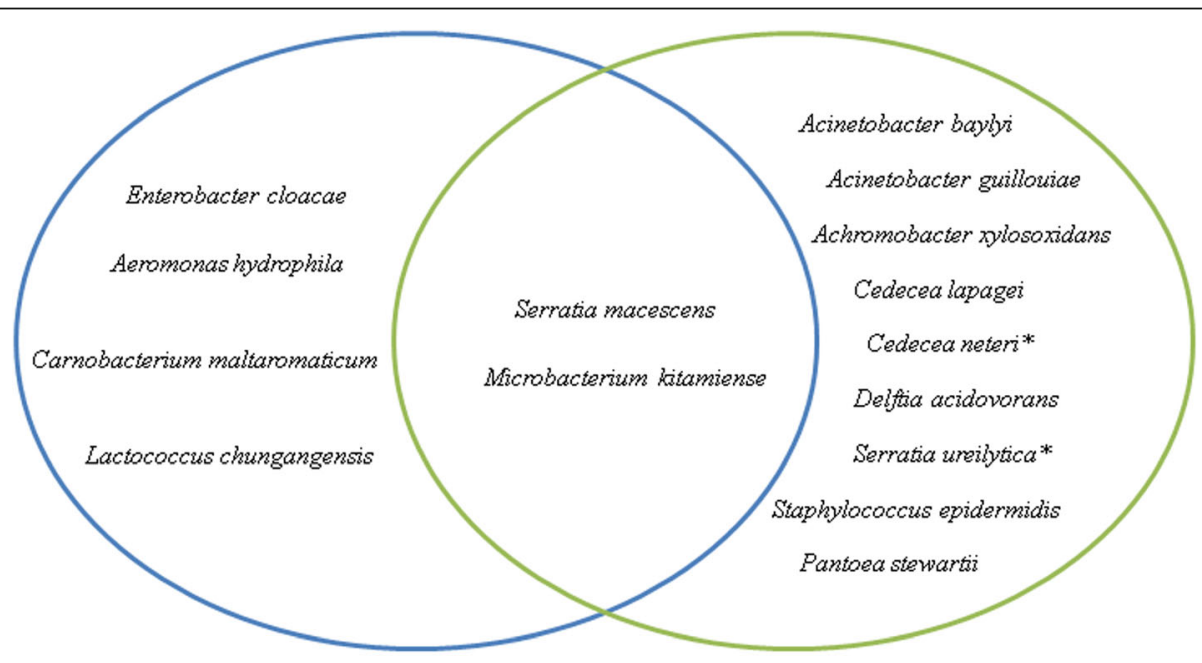

\section{Breeding water}

Aedes albopictus

Fig. 1 Isolation and identification of bacteria in the breeding water and midgut of an Aedes albopictus laboratory colony (Marseille, France). Bacterial species reported for the first time in Aedes albopictus microbiota are indicated by an asterisk (*) 
marcescens, Serratia ureilytica, Staphylococcus epidermidis, Pantoea stewartii and Microbacterium kitamiense were less frequently represented (Fig. 1). The breeding water of Ae. albopictus was analysed, and five bacterial species were identified (Fig. 1). Among them, Serratia marcescens and Microbacterium kitamiense were found both in the Ae. albopictus mosquito midguts and their breeding water. Three genera, Aeromonas, Carnobacterium and Lactobacillus, were found only in the breeding water (Fig. 1).

\section{Mosquitoes collected in the field and their breeding water}

Five distinct bacterial species were isolated from the midguts of Ae. albopictus field-collected mosquitoes (Marseille), including four genera: Bacillus, Micrococcus, Staphylococcus and Serratia (Fig. 2).

Serratia marcescens bacteria were common in the Ae. albopictus mosquito midguts and their breeding water. Eleven bacterial species from five genera, Aeromonas, Clostridium, Enterococcus, Lactococcus and Morganella, were found only in their breeding water.

The gut microbiota of An. gambiae in the wild (Mali) was composed of ten bacterial species from seven genera: Enterobacter, Pasteurella, Pseudomonas, Bacillus, Enterococcus, Staphylococcus and Kocuria (Fig. 3).

Midgut microbiota of $C$. quinquefasciatus from Mali was composed of five bacterial species from five genera: Pseudomonas, Escherichia, Propionibacterium, Staphylococcus and Lactobacillus (Fig. 3).

In breeding water sites, 51 bacterial species were cultivated representing 15 genera: Acinetobacter, Aeromonas, Arthrobacter, Bacillus, Clostridium, Delftia, Enterococcus, Lactococcus, Lysinibacillus, Pseudomonas,
Raoultella, Robinsonella, Rothia, Shewanella and Serratia. Two bacterial species, Bacillus cereus and Enterococcus faecium, were common to the An. gambiae wild strains and breeding water (Fig. 3, Table 4).

\section{Discussion}

This work analysed the midgut microbiota composition of mosquitoes reared in the laboratory and collected in the wild and compared this midgut microbiota diversity with their respective breeding sites, using an original strategy based on a special culture, the culturomics technique.

Furthermore, for the definitive identification of mosquitoes collected in the field, a new innovative method based on the analysis of mosquito leg protein spectra obtained by MALDI-TOF MS was used [19, 28].

This approach has been applied here for the first time to mosquitoes collected in the field from Africa. This is further evidence that use of MALDI-TOF MS to identify mosquitoes is a rapid, accurate analysis technique, at low cost in terms of consumables [19, 28].

Several previous studies have already analysed mosquito microbiota and the water of their respective breeding sites [10]. Most of these studies used molecular approaches, mainly based on analysing sequences of the $16 \mathrm{~S}$ ribosomal RNA gene and cultures of mosquito midgut microbiota [10, 29].

The culturomics approach used in this work revealed a wide diversity of the midgut microbiota of $A n$. gambiae (wild and laboratory strains), Ae. albopictus (wild and laboratory strains) and C. quinquefasciatus (wild strains).

The majority of the bacteria detected in the microbiota of mosquitoes were gram-negative and belong to the

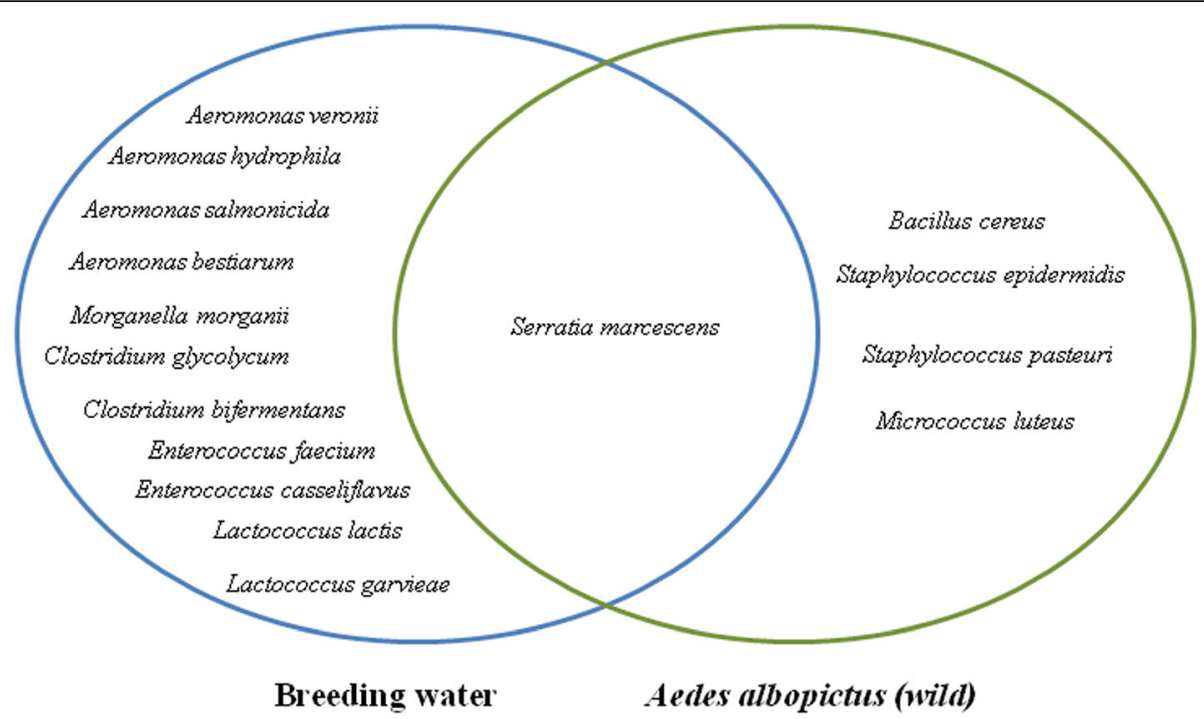

Fig. 2 Isolation and identification of bacteria in the breeding water and midgut of Aedes albopictus wild colonies (Marseille, France) 


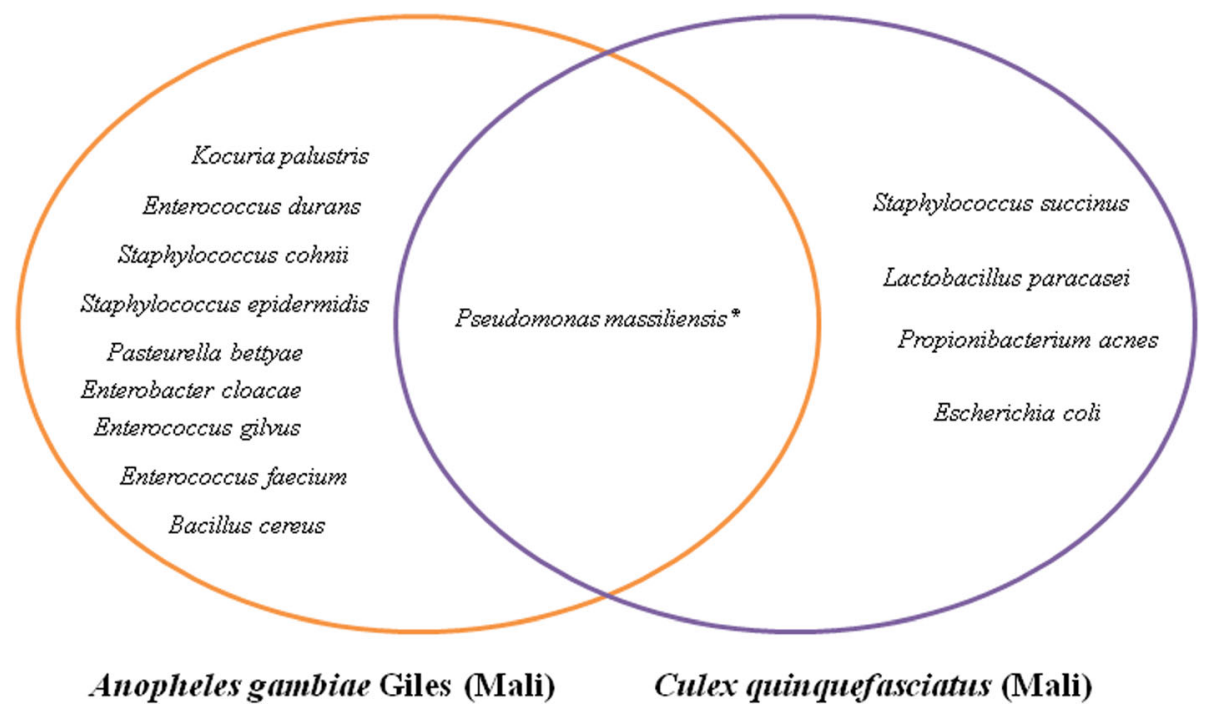

Fig. 3 Isolation and identification of bacteria in the midgut of Anopheles gambiae and Culex quinquefasciatus wild colonies in Sikasso (Mali). Bacterial species reported for the first time in Anopheles gambiae and Culex quinquefasciatus microbiota are indicated by an asterisk $(*)$

phylum Proteobacteria, similar to other studies [10, 29]. However, 17 new bacterial species not previously identified in An gambiae midgut microbiota have been isolated here: Serratia ureilytica, Enterobacter kobei, Enterococcus faecium, Enterococcus avium, Enterococcus raffinosus, Elizabethkingia miricola, Acinetobacter baylyi, Cedecea neteri, Enterobacter asburiae, Pseudomonas gessardii, Streptococcus sanguinis, Streptococcus mitis, Staphylococcus epidermidis, Clostridium perfringens, Microbacterium maritypicum, Pseudomonas massiliensis and Rhodococcus erythropolis.

Interestingly, among the bacterial colonies submitted to MALDI-TOF MS identification, one isolated in breeding water (Mali) was not identified, and corresponded to Lactococcus chungangensis according to $16 \mathrm{~S}$ sequencing. This bacterial species was then implemented in the MALDI-TOF MS.

Moreover, a bacterial species, Pseudomonas massiliensis, recently isolated in the Timone laboratory, which is under description (D. Raoult, personal communication), was isolated in the An. gambiae and C. quinquefasciatus midgut and their breeding water collected from Mali.

Six bacterial species were commonly found in the midgut of An. gambiae laboratory colonies from Marseille and its respective breeding water. Moreover, 12 and seven bacterial species were found only in the midgut of An. gambiae laboratory colonies from Marseille and its breeding water, respectively. Three bacterial species (Enterococcus faecium, Enterobacter cloacae and Staphylococcus epidermidis) were commonly found both in the midgut of An. gambiae wild strains and laboratory strains.

The gut microbiota of An. gambiae in the wild (Mali) was composed of seven genera: Enterobacter, Pasteurella,
Pseudomonas, Bacillus, Enterococcus, Staphylococcus and Kocuria. The gut microbiota of An. gambiae from field collection (Cameroon) was found to be dominated by Comamonas, Serratia, Pseudomonas, Burkholderia and Brevundimonas bacteria by pyrosequencing analysis [30].

We found that some bacterial species were common in the midgut of An. gambiae and Ae. albopictus laboratory strains.

Comparing the Ae. albopictus laboratory strain with those of the Ae. albopictus wild strain, we observed that Serratia marcescens was the only bacterial species found in common. Eight bacterial species were only found in the midgut of Ae. albopictus in the laboratory. Conversely, four were specific for the midguts of the Ae. albopictus wild strain. A difference was observed between the midgut microbiota of Ae. albopictus laboratory and wild strains. In addition to the contribution to the knowledge of bacterial species associated with the microbiota of mosquito vectors, these results suggest that the environment plays a major role in variations of the midgut microbiota diversity of mosquitoes. All the bacteria isolated from the laboratory and wild mosquito microbiota and breeding water are ubiquitous in the environment and are found in water and soil, as well in association with plants, insects, humans and other animals [31-33]. These results correlate with other studies; namely that the environmental conditions of the vectors are key determinants in shaping the midgut microbiota [24].

The main limitation of our growth conditions is that culturomics does not allow the growth of some strictly anaerobic bacteria [14]. Strategies are currently under development by the team culturomics to enable the growth of these bacteria considered uncultured by culturomics [34]. 
Table 4 Composition of the microbiota of three breeding water samples in Sikasso (Mali)

\begin{tabular}{|c|c|c|c|}
\hline Bacteria & $\begin{array}{l}\text { Breeding } \\
\text { water } 1\end{array}$ & $\begin{array}{l}\text { Breeding } \\
\text { water } 2\end{array}$ & $\begin{array}{l}\text { Breeding } \\
\text { water } 3\end{array}$ \\
\hline Acinetobacter Iwoffii & $\times$ & & $\times$ \\
\hline Acinetobacter towneri & $\times$ & & \\
\hline Aeromonas hydrophila & $\times$ & & \\
\hline Aeromonas veronii & $\times$ & & \\
\hline Arthrobacter gandavensis & & $x$ & \\
\hline Bacillus cereus & $x$ & $\times$ & $\times$ \\
\hline Bacillus idriensis & $\times$ & & \\
\hline Bacillus megaterium & & & $x$ \\
\hline Clostridium absonum & & & $\times$ \\
\hline Clostridium amylolyticum & & & $x$ \\
\hline $\begin{array}{l}\text { Clostridium } \\
\text { anorexicamassiliense }\end{array}$ & $\times$ & $x$ & $\times$ \\
\hline Clostridium aerotolerans & $\times$ & & \\
\hline Clostridium butyricum & & $x$ & $x$ \\
\hline Clostridium bifermentans & $\times$ & $\times$ & $\times$ \\
\hline Clostridium cadaveris & & & $x$ \\
\hline Clostridium celerecrescens & $\times$ & $x$ & \\
\hline Clostridium collagenovorans & & & $x$ \\
\hline Clostridium glycolycum & $\times$ & & $\times$ \\
\hline Clostridium ihumii & & & $x$ \\
\hline Clostridium lituseburense & $\times$ & $x$ & $\times$ \\
\hline Clostridium $n$ & $\times$ & & $\times$ \\
\hline Clostridium perfringens & & $\times$ & \\
\hline Clostridium sardiniense & & & $x$ \\
\hline Clostridium sartagoforme & $\times$ & & \\
\hline Clostridium senegalensis & & $x$ & \\
\hline Clostridium sordellii & & $\times$ & \\
\hline Clostridium sphenoides & & $x$ & \\
\hline Clostridium sporogenes & $\times$ & & \\
\hline Clostridium tertium & $\times$ & & $x$ \\
\hline Delftia acidovorans & & $\times$ & \\
\hline Enterococcus casseliflavus & $\times$ & $\times$ & $x$ \\
\hline Enterococcus faecium & $\times$ & $\times$ & $\times$ \\
\hline Enterococcus hirae & & $x$ & $x$ \\
\hline Enterococcus italicus & & & $x$ \\
\hline Enterococcus mundtii & & $x$ & \\
\hline \multicolumn{4}{|l|}{ Enterococcus termitis } \\
\hline Lactococcus chungangensis & $x$ & $x$ & $\times$ \\
\hline Lysinibacillus sphaericus & & $\times$ & \\
\hline Pseudomonas chlororaphis & & $\times$ & \\
\hline Pseudomonas corrugata & & $\times$ & \\
\hline Pseudomonas fluorescens & $x$ & & \\
\hline Pseudomonas jessenii & & $\times$ & \\
\hline Pseudomonas monteilii & $x$ & & \\
\hline
\end{tabular}

Table 4 Composition of the microbiota of three breeding water samples in Sikasso (Mali) (Continued)

\begin{tabular}{|c|c|c|c|}
\hline Bacteria & $\begin{array}{l}\text { Breeding } \\
\text { water } 1\end{array}$ & $\begin{array}{l}\text { Breeding } \\
\text { water } 2\end{array}$ & $\begin{array}{l}\text { Breeding } \\
\text { water } 3\end{array}$ \\
\hline Pseudomonas putida & $\times$ & $x$ & \\
\hline Pseudomonas rhodesiae & $\times$ & & \\
\hline Pseudomonas tolaasii & $x$ & & \\
\hline Raoultella ornithinolytica & & $\times$ & \\
\hline Robinsoniella peoriensis & & $\times$ & \\
\hline Rothia aeria & $\times$ & & \\
\hline Shewanella profunda & $\times$ & & \\
\hline Serratia fonticola & & $x$ & $x$ \\
\hline
\end{tabular}

Presence of bacteria is indicated by $x$

Bold corresponds to bacterial species common in the midgut and

breeding water

The sample size of laboratory mosquitoes used in this study is higher than the number of wild mosquitoes collected; this may explain the increase in the number of bacteria isolated in the laboratory mosquitoes.

Despite the previous studies of the mosquito midgut microbiota, it is still necessary to extend our knowledge in this domain by using new tools for exploration, such as culturomics. This culturomics approach allowed the isolation of bacterial species not previously associated with these vectors, and will aid the development of new control strategies for mosquito-borne diseases.

\section{Conclusions}

To conclude, diverse bacterial species were found in common in the midguts of adult An. gambiae, Ae. albopictus and C. quinquefasciatus and in breeding water. The majority of the bacterial species belong to the phyla Proteobacteria and Firmicutes. Culturomics allowed the isolation of bacterial species identified for the first time in An. gambiae midgut. This study demonstrates a wide diversity of new species of bacteria associated with the mosquito microbiota, which may be targets for vector control strategies. Our study shows that the immediate environment plays an important role in the acquisition of bacteria by the mosquito. The innovative culturomics technique and MALDI-TOF MS application are evidence of the growth and correct identification of bacteria, isolated without ambiguity from the mosquito microbiota.

\footnotetext{
Acknowledgments

We would like to acknowledge Prof. D. Fontenille (IRD, Montpellier, France) for providing Anopheles gambiae laboratory colonies, Dr. Jean-Christophe Lagier for sharing his culturomics expertise, Constentin Dieme for help with mosquito dissection, and Sirama Niaré, who introduced me to mosquito identification by MALDI-TOF and sequencing. This work has been carried out with the support of the $A^{*}$ MIDEX project (No. ANR-11-IDEX-0001-02) funded by the "Investissements d'Avenir" French Government program, managed by the French National Research Agency (ANR) and the Foundation Mérieux grant to MRTC for the field specimens collection.
} 


\section{Funding}

This manuscript has been reviewed and corrected by American journal experts. This work has been carried out thanks to the support of the $A^{*}$ MIDEX project ( $n^{\circ}$ ANR-11-IDEX-0001-02) funded by the Investissements d'Avenir French Government programme, managed by the French National Research Agency (ANR).

\section{Availability of data and material}

Not applicable

\section{Authors' contributions}

Designed and developed the experiments: AL, PP. Performed the experiments: TF, KKA. Analyzed the data: AL, TF, PP. Contributed reagents/ materials/ analysis tools: DKO, RD. Wrote the paper: TF, AL, PP. Contributed to the paper redaction: $\mathrm{DKO}, \mathrm{RD}$. All authors read and approved the final version of the manuscript.

\section{Competing interests}

The authors declare that they have no competing interests.

\section{Consent for publication}

Not applicable.

\section{Ethics approval and consent to participate}

Consent was obtained from volunteer landing catches collectors. Ethical approval for the mosquito monitoring was granted by authorities from the National Malaria Control Program (NMCP) and approved by the faculty of medicine ethical committee, Bamako, Mali (N²011 89 FMPOS).

\section{Author details}

'Unité de Recherche en Maladies Infectieuses et Tropicales Emergentes (URMITE), UM63, CNRS 7278, IRD 198 (Dakar, Sénégal), Inserm 1095, Faculté de Médecine, Aix Marseille Université, 27 bd Jean Moulin, 13385 Marseille cedex 5, France. ${ }^{2}$ Department of Epidemiology of Parasitic Diseases, Malaria Research and Training Center, University of Science, Techniques and Technologies of Bamako, Bamako, Mali. ${ }^{3}$ Département d'Infectiologie de Terrain, Unité de Parasitologie, Institut de Recherche Biomédicale des Armées, Marseille, France.

Received: 13 October 2015 Accepted: 25 August 2016

Published online: 10 September 2016

\section{References}

1. Becker N, Petrić D, Zgomba M, Boase C, Dahl C, Lane J, Kaiser A. Mosquitoes and Their Control. New York: Kluwer Academic/Plenum Publishers; 2003. p. 498.

2. Klempner MS, Unnasch TR, Hu LT. Taking a bite out of vector-transmitted infectious diseases. N Engl J Med. 2007;356:2567-9.

3. Wilson ME, Weld LH, Boggild A, Keystone JS, Kain KC, von Sonnenburg F, Schwartz E. Fever in returned travelers: results from the GeoSentinel Surveillance Network. Clin Infect Dis. 2007:44:1560-8.

4. Paupy C, Delatte H, Bagny L, Corbel V, Fontenille D. Aedes albopictus, an arbovirus vector: from the darkness to the light. Microbes Infect. 2009;11: $1177-85$.

5. Wong PS, Li MZ, Chong CS, Ng LC, Tan CH. Aedes (Stegomyia) albopictus (Skuse): a potential vector of Zika virus in Singapore. PLoS Negl Trop Dis. 2013;7:e2348.

6. Raghavendra K, Barik TK, Reddy BP, Sharma P, Dash AP. Malaria vector control: from past to future. Parasitol Res. 2011:108:757-79.

7. Tchioffo MT, Boissiere A, Churcher TS, Abate L, Gimonneau G, Nsango SE, et al. Modulation of malaria infection in Anopheles gambiae mosquitoes exposed to natural midgut bacteria. PLoS One. 2013;8:e81663.

8. Yun JH, Roh SW, Whon TW, Jung MJ, Kim MS, Park DS, et al. Insect gut bacterial diversity determined by environmental habitat, diet, developmental stage, and phylogeny of host. Appl Environ Microbiol. 2014; 80:5254-64.

9. Ricci I, Damiani C, Capone A, DeFreece C, Rossi P, Favia G. Mosquito/ microbiota interactions: from complex relationships to biotechnological perspectives. Curr Opin Microbiol. 2012;15:278-84.

10. Minard G, Mavingui $P$, Moro CV. Diversity and function of bacterial microbiota in the mosquito holobiont. Parasit Vectors. 2013;6:146.
11. Dong Y, Manfredini F, Dimopoulos G. Implication of the mosquito midgut microbiota in the defense against malaria parasites. PLoS Pathog. 2009;5:e1000423.

12. Beier MS, Pumpuni CB, Beier JC, Davis JR. Effects of para-aminobenzoic acid, insulin, and gentamicin on Plasmodium falciparum development in anopheline mosquitoes (Diptera: Culicidae). J Med Entomol. 1994;31:561-5.

13. Gendrin M, Rodgers FH, Yerbanga RS, Ouedraogo JB, Basanez MG, Cohuet A, Christophides GK. Antibiotics in ingested human blood affect the mosquito microbiota and capacity to transmit malaria. Nat Commun. 2015;6:5921.

14. Lagier JC, Armougom F, Million M, Hugon P, Pagnier I, Robert C, et al. Microbial culturomics: paradigm shift in the human gut microbiome study. Clin Microbiol Infect. 2012;18:1185-93.

15. Awono-Ambene HP, Diawara $L$, Robert V. Comparison of direct and membrane feeding methods to infect Anopheles arabiensis with Plasmodium falciparum. Am J Trop Med Hyg. 2001;64(1-2):32-4.

16. Moutailler S, Bouloy M, Failloux AB. Short report: efficient oral infection of Culex pipiens quinquefasciatus by Rift Valley fever virus using a cotton stick support. Am J Trop Med Hyg. 2007;76(5):827-9.

17. Hervy J, Le Goff G, Geoffroy B, Herve J and Manga L. Les Anopheles de la région Afro-tropicale, logiciel d'identification et d'ensegnement, Collection didactique. version ORSTOM. 1998

18. Yssouf A, Flaudrops C, Drali R, Kernif T, Socolovschi C, Berenger JM, et al. Matrix-assisted laser desorption ionization-time of flight mass spectrometry for rapid identification of tick vectors. J Clin Microbiol. 2013;51:522-8.

19. Yssouf A, Socolovschi C, Flaudrops C, Ndiath MO, Sougoufara S, Dehecq JS, et al. Matrix-assisted laser desorption ionization-time of flight mass spectrometry: an emerging tool for the rapid identification of mosquito vectors. PLoS One. 2013;8:e72380.

20. Yssouf A, Almeras L, Terras J, Socolovschi C, Raoult D, Parola P. Detection of Rickettsia spp. in ticks by MALDI-TOF MS. PLoS Negl Trop Dis. 2015;9: e0003473.

21. Folmer O, Black M, Hoeh W, Lutz R, Vrijenhoek R. DNA primers for amplification of mitochondrial cytochrome c oxidase subunit I from diverse metazoan invertebrates. Mol Mar Biol Biotechnol. 1994;3(5):294-9.

22. Fanello C, Santolamazza F, della Torre A. Simultaneous identification of species and molecular forms of the Anopheles gambiae complex by PCR-RFLP. Med Vet Entomol. 2002;16:461-4.

23. Straif SC, Mbogo CN, Toure AM, Walker ED, Kaufman M, Toure YT, Beier JC. Midgut bacteria in Anopheles gambiae and An. funestus (Diptera: Culicidae) from Kenya and Mali. J Med Entomol. 1998;35:222-6.

24. Boissiere A, Tchioffo MT, Bachar D, Abate L, Marie A, Nsango SE, et al. Midgut microbiota of the malaria mosquito vector Anopheles gambiae and interactions with Plasmodium falciparum infection. PLoS Pathog. 2012;8: e1002742.

25. Pfleiderer A, Lagier JC, Armougom F, Robert C, Vialettes B, Raoult D. Culturomics identified 11 new bacterial species from a single anorexia nervosa stool sample. Eur J Clin Microbiol Infect Dis. 2013:32:1471-81.

26. Seng P, Drancourt M, Gouriet F, La SB, Fournier PE, Rolain JM, Raoult D. Ongoing revolution in bacteriology: routine identification of bacteria by matrix-assisted laser desorption ionization time-of-flight mass spectrometry. Clin Infect Dis. 2009:49:543-51.

27. Stackebrandt E, Pauker O, Steiner U, Schumann P, Straubler B, Heibei S, Lang E. Taxonomic characterization of members of the genus Corallococcus: molecular divergence versus phenotypic coherency. Syst Appl Microbiol. 2007:30:109-18.

28. Yssouf A, Almeras L, Raoult D, Parola P. Emerging tools for identification of arthropod vectors. Future Microbiol. 2016;11:549-66.

29. Yadav KK, Bora A, Datta S, Chandel K, Gogoi HK, Prasad GB, Veer V. Molecular characterization of midgut microbiota of Aedes albopictus and Aaedes aegypti from Arunachal Pradesh, India. Parasit Vectors. 2015;8:641.

30. Tchioffo MT, Boissière A, Abate L, Nsango SE, Bayibéki AN, Awono-Ambéné $\mathrm{PH}$, et al. Dynamics of bacterial community composition in the malaria mosquito's epithelia. Front Microbiol. 2016;6:1500.

31. Teo J, Tan SY, Liu Y, Tay M, Ding Y, Li Y, et al. Comparative genomic analysis of malaria mosquito vector-associated novel pathogen Elizabethkingia anophelis. Genome Biol Evol. 2014:6:1158-65.

32. Iguchi A, Nagaya Y, Pradel E, Ooka T, Ogura Y, Katsura K, et al. Genome evolution and plasticity of Serratia marcescens, an important multidrugresistant nosocomial pathogen. Genome Biol Evol. 2014;6:2096-110. 
33. Roux V, Million M, Robert C, Magne A, Raoult D. Non-contiguous finished genome sequence and description of Oceanobacillus massiliensis sp. nov. Stand Genomic Sci. 2013;9:370-84.

34. Lagier J-C, Hugon P, Khelaifia S, Fournier P-E, La SB, Raoult D. The rebirth of culture in microbiology through the example of culturomics to study human Gut microbiota. Clin Microbiol Reviews. 2015;28:1.

Submit your next manuscript to BioMed Central and we will help you at every step:

- We accept pre-submission inquiries

- Our selector tool helps you to find the most relevant journal

- We provide round the clock customer support

- Convenient online submission

- Thorough peer review

- Inclusion in PubMed and all major indexing services

- Maximum visibility for your research

Submit your manuscript at www.biomedcentral.com/submit 